\title{
Understanding Jerusalem and its Cross-Cultural Dilemmas in Guy Delisle's Jerusalem: Chronicles From the Holy City
}

\author{
Ana-Maria GAVRILĂ \\ University of Bucharest (Romania) \\ Centre of Excellence in Image Studies \\ anamaria.gavrila@hotmail.com
}

\begin{abstract}
Guy Delisle's Jerusalem: Chronicles from the Holy City (2011) is a nonfictional graphic novel which narrates the experiences during a year that the Canadian artist and his family spent living far from home, in the occasionally dangerous and perilous city of the ancient Middle East. Part humorous memoir filled with "the logistics of everyday life," part an inquisitive and sharp-eyed travelogue, Jerusalem is interspersed with enthralling lessons on the history of the region, together with vignettes of brief strips of Delisle's encounters with expatriates and locals, with Jewish, Muslim, and Christian communities in and around the city, with Bedouins, Israeli and Palestinians. Since the comic strip is considered amongst the privileged genres able to disseminate stereotypes, Jerusalem tackles cultural as well as physical barriers, delimiting between domestic and foreign space, while revealing the historical context of the Israeli-Palestinian present conflict. Using this idea as a point of departure, I employ an imagological method of interpretation to address cross-cultural confusions in analysing the cartoonist's travelogue as discourse of representation and ways of understanding cultural transmission, paying attention to the genre's convention, where Delisle's drawing style fits nicely the narrative techniques employed. Through an imagological perspective, I will also pay attention to the interaction between cultures and the dynamics between the images which characterise the Other (the nationalities represented or the spected) and those which characterise - not without a sense of irony - his own identity (self-portraits or auto-images). I shall take into account throughout my analysis that the source of this graphic memoir is inevitably a subjective one: even though Delisle professes an unbiased mind-set from the very beginning, the comic is at times coloured by his secular views. Delisle's book is a dark, yet gentle comedy, and his wife's job at the Doctors Without Borders paired with his personal experiences are paradoxically a gentle reminder that “There'll always be borders." In sum, the comic medium
\end{abstract}


brings a sense of novelty to the imagological and hermeneutic conception of the interpretation of cultural and national stereotypes and/or otherness in artistic and literary works.

Keywords: graphic memoir, travelogue, images of the other, self-image, travelling and languages

I can almost tell, in set phrase, what [travellers] will say when they see Tabor, Nazareth, Jericho and Jerusalem - because I have the books they will "smouch" their ideas from ... The Pilgrims will tell of Palestine, when they get home, not as it appeared to them, but as it appeared to Thompson and Robinson and Grimes - with the tints varied to suit each pilgrim's creed.

(Mark Twain, The Innocents Abroad, or The New Pilgrim's Progress, 1869)

Here was an object: Up and do!/ With seed and tillage help renew - / Help reinstate the Holy Land.

(Herman Melville, Clarel: A Poem and Pilgrimage in the Holy Land, 1876)

Guy Delisle is a Canadian cartoonist and former studio animator, who has become internationally known for moving to foreign places and drawing casual vignettes on cross-cultural dilemmas. Over the past decade - as a result of his wife's work with Médecins Sans Frontiéres, or Doctors Without Borders -, he has documented his travels to China (Shenzhen, 2000), North Korea (Pyongyang, 2003), and Burma, now Myanmar (Chroniques birmanes, 2007). Like the other three published books which had resulted from those trips, Jerusalem: Chronicles from the Holy City (Drawn and Quarterly, 2011) is a travelogue, which even though it borrows from history, geography, anthropology, and social science, it is not automatically a literary reportage.

Jerusalem: Chronicles from the Holy City is Guy Delisle's biggest and most accomplished autobiographical comic to date, not just because of the number of pages or because he finds himself inside the walls of one of the most secretive places on earth, but because he is approaching it from a very particular place: one where he is as excited to find an ancient settlement as he is to find a playground with a really good slide for his two young children. The cultural and physical barriers between the Jewish, Muslim, Armenian and Christian communities in and around The Old City, and the compromises and workarounds that the city's residents have been forced to contrive, become the source of a gloomy, yet gentle ubiquitous comedy: absurdity on the very edge of tragedy. 


\section{"Homo Viator" in the Holy Land, Israel, and Palestine}

In the nineteenth century, travel writings about the Holy Land were extremely popular. Travellers were thrilled to enter the holy city of Jerusalem for the first time, in addition to experiencing the exoticism of the East. There are, however, dramatic discrepancies between the nineteenth and twentieth-century travel books, attributable to the stark changes in the state of affairs in the region, from one century to the next. But their authors share certain manners of response to the complex religious and psychological encounter with the idea of a sacred land (Obenzinger 2009).

A journey to the Holy Land was a mighty theme, as Melville would advocate in his epic poem Clarel, and these travel accounts share a number of stylistic conventions and attitudes, as they attempt a mighty response. Mark Twain, Walter Scott, Herman Melville, Hannah Arendt, and Saul Bellow have produced some of the best literary works based on their journey to Jerusalem. This large and growing collection joins other texts and cultural objects - paintings, religious tracts, standard guidebooks, photographs, brochures, and more - within a major enthralment with The Old City, which persists during the course of both centuries.

The vast library of American and European Holy Land books perpetuated a thick textual lens. Consequently, the encounter with the actual place was relentlessly being mediated through an elaborate set of repeated travel and literary devices (Obenzinger 2009). These accounts were so plenteous and so overwrought that Mark Twain could have easily written his Holy Land travelling letters without even having to set foot in Jerusalem.

Contact with its real people and conditions conflicted with what they had visualised when they had read the Bible back home. Discovering the sacred amongst the mundane, i.e. "evidences" of biblical truth and prophetic fulfilment in the land of Palestine, invoked the believer's special relationship to the holy city.

In the study at hand I chose to focus my imagological interpretation of national and ethnic strangeness and/or otherness in Guy Delisle's graphic travelogue firstly because writing about the Holy Land in an original fashion in the twenty-first century is not easy. Traditionally, those who travelled to The Old City would read the Holy Land, their comprehension often confirming all of their deepest, most conventional beliefs, developing a sense of "sacred theatricality" which allowed them "to cultivate epiphanies or to stage biblical re-enactment" (Obenzinger 2009, 151). The Canadian cartoonist chose to resist the perpetuation or reinstallment of the travel writing conventions by challenging the shared orientalist stereotypes and myths of the Holy Land: "Arabs were often described as dirty, violent, and ignorant [...]; Muslims were generally regarded with disgust, while Jews were generally depicted as uncouth and pathetic" (Obenzinger 2009, 151-152). Secondly, graphic novels, similar to travel writings, are among the most hybrid 
and unassimilable of literary genres. Jerusalem: Chronicles from the Holy City is a "useful vehicle for cultural self-perception," a "barometer for changing views on other ('foreign', 'non-Western') cultures," and a "trigger for the informational circuits that tap us into the wider world" (Holland and Huggan 2000, XIII).

\section{A cartoonist's travelogue and the conventions of the genre}

In the first chapter of the graphic novel, marked "August," the autobiographical protagonist is on the plane to Jerusalem. It is 2008. Next to him, he is surprised to see a cheerful Russian old man with concentration-camp serial numbers tattooed along his forearm, who manages to calm Delisle's baby daughter: "We've seen so many horrific images from that time in history," he remarks, "that my imagination just takes off. But I'm treated to a whole other picture tonight, as this old Russian plays with my daughter thousands of feet in the air" $(2012,7) .{ }^{1}$ The scene serves an important function to Delisle's travelling narrative, as he warns himself (and, by extension, his readers) not to let the images and stories he had seen and heard about Jerusalem affect his impression of the city. By admitting a certain degree of ignorance and committing to an unprejudiced, unbiased mind-set at the book's outset, he allows himself to ask straightforward, innocent questions (e.g. from Jerusalem: "So ... we're in Israel, right?" The answer is not as simple as one might think: "Uh... Yes... Well, it depends") (15). Delisle seems to have cast aside prior knowledge of the Israeli-Palestinian conflict, or even moments from the history and traditions of the Holy Land, as it has been portrayed by the media, asking his own questions and exploring the city in a more (self-)reflexive manner.

Guy Delisle has a genuine talent for visual storytelling, carefully choosing which moments to draw into sequential panels - what to leave out, what to include - and correspondingly for outlining environments: religious shrines and settlements, but also grocery stores, markets, cafés, playgrounds and checkpoints - plenty of checkpoints. "Today, we'll go have a look at the Qalandiya checkpoint. Since it's Ramadan and many Muslims want to pray at the great mosque in Jerusalem on Fridays, there could be trouble. I hadn't seen the separation wall yet. Huh..." he adds, "I didn’t think it would be so high" (39).

Each community in Jerusalem (the Christian quarter, the Armenian quarter and the Jewish quarter) lives by its own rules, and Delisle and his family have to be careful enough to respect all of them: the "Christian-run store, it's closed on Sundays, but it's the only place in Beit Hanina" - in the east of Jerusalem,

1 As follows, the quotes from Guy Delisle's 2012 graphic novel will only be referenced with the page number. 
where the protagonist lives - "that sells beer and wine," another place, which is Muslim, closes on Fridays - "You'll never find alcohol here," plus one last shopping centre where, although it is in a settlement and closed for Sabbath (on Saturdays), "they do sell alcohol" (16). It may seem a rather trivial matter, but the members of these communities take themselves - and consequently the selling or non-selling of alcohol - very seriously. Beit Hanina, which is a Palestinian neighbourhood, on the East part of Jerusalem, is actually "an Arab village that was annexed [to The Old City] following the six-day war in '67" (15). The arid landscape of the area contrasts strongly with the West Jerusalem, where - to Delisle's amazement - there are "Ah! Real sidewalks!,” an outdoor café, a park with a playground, a market, "and garbage cans that aren't overflowing” (25). Even though "the city is a ghost town on the Sabbath," the discrepancies between the east and the west are sometimes shocking (25).

In the course of one year, the protagonist explores the Holy City, going to the very edges of the Israeli/Arab borders and seeing what he finds there, how the cultures clash at the meeting point: "In passing, they tell us how to get to The Old City. Again, it's complicated. Jerusalem has two parallel transportation systems. There are the Israeli buses that go everywhere except the Arab quarters. And there are the Arab minivans that operate nowhere but the Arab quarters" (39). Each situation is carefully drawn in parallel panels.

Sometimes it is a physical barrier which he encounters, like the high separation wall he becomes obsessed with - and which he sketches from countless angles before he is moved on by confused officers playing it safe -, and other crossing points: "Nadège is going to Gaza today. Out of curiosity, I'm joining her until Erez, the only crossing point between Gaza and Israel" (83). Sometimes the barrier is a psychological one:

We stop for a mint lemonade. The feel of the place is something else. To the left, police and soldiers are filling out a report. People clamour around with their version of events. In the meantime, a line of tourists clears a path through the tables to reach an ATM. And opposite, a group of Italians stop to pray in front of a small chapel. (18)

Thanks to his insightful explanations and drawings, one may observe the different modalities of acting and interacting with one another. The strangeness manifests itself as an impossibility to speak, to communicate, and to understand each other.

In the 300 or so pages of Jerusalem, Delisle skilfully presents episodes from his daily life interspersed with engaging lessons on the history of the region. For example, 
Hebron is divided into two areas: $\mathrm{H} 1$ and $\mathrm{H} 2$. $\mathrm{H} 1$ is controlled by the Palestinians and $\mathrm{H} 2$ is controlled by the Israeli army to protect the settlers, who live in houses not far away from the Tomb of the Patriarchs. [...] It seems like Hebron's history ever since can be summed up by two dates: in 1929, Arabs went on a rampage and killed sixty-seven Jews; in 1994, a Jew gunned down twenty-nine Palestinians praying at the Tomb of the Patriarchs. (118)

Concluding rather penetratingly: "Each community has its massacre" (118). These comments are attached to symbolic illustrations depicting past massacres, events which Delisle did not witness first-hand, but which he imagines and shares with his reader as part of a larger cultural and historical context.

Delisle's drawing style of such moments fits nicely with his narration. His outlines are plain, clean, and casual, without being sloppy, stripping down an image to its essential "meaning," thus amplifying that particular meaning in a way in which a detailed description or a more realistic image could not exemplify (McCloud 1993). Most of Delisle's frames are in blue and brown hues, serving as backdrop for the mundane streets, with colour (bold reds, greens and yellows) used from time to time - as if to prove that the history and culture of the Other is never black and white, but always nuanced - to highlight and bring attention to a map ["The O.C.H.A. office is on the green line. The famous green line was pencilled on a map at the end of the first Israeli-Arab war (in 1948) by generals from both sides, dividing the territory between the new Israeli nation and a future Palestine," (33)]; a loud obnoxious noise, e.g. gunshot sounds ["Bang! Bang! Tear gas grenades to scatter people." (45)]; a memory or an intensely violent event: "Tension mounts, spectators push and shove, the chanting stops and all at once the animals' throats are slit. Blood spurts, soiling the immaculate white clothes of the slaughterers" (252). Similarly, maps perform a particularly important function in signalling the authenticity of autobiographical comics, "particularly because they seem to provide clear, unambiguous links between locations in a narrative and actual places in the real world" (El Refaie 2012, 158).

$\mathrm{He}$ is also a specialist in compressing these historical scenes to just a few panels, phrases, and sometimes even gestures. Most of the subchapters in Jerusalem are just one, two, or three pages in length. They're all vignettes, and many of them involve driving the kids to school, taking them on vacations, or simply wandering around trying to find a place to get some drawing done before they have to come home.

But there are also encounters and interactions, with other expats, with locals, with Jews and Muslims and Christians, with Israelis and Palestinians. The portraits always bear recognisable elements of their origins, nationality, religion and social status: "I learn all kinds of things. The men in the stripped coats are of 
Hungarian descent. The Haredim are divided into several subgroups of which the Hassidim are the best known. Certain small details help tell them apart: a flatter hat, worn a certain way, a shorter vest [...]" (296).

The protagonist is also exploring the politics of the region, which are as complex and complicated as they come, but he wisely allows these issues to be explained by locals:

He briefly explains how they differ from Israeli Jews. 'Jerusalem isn't sacred in any way. It is just another city. Unlike the Jews, we Samaritans have never left the Holy Land. The Samaritans are considered to be Jews by the Israeli government, but not by the ultra-orthodox). They also have Palestinian ID cards, and Jordanian passports too. You could say they're at crossroads.' (220)

With so much to see and learn about, Jerusalem: Chronicles from the Holy City was always going to be Delisle's longest work, but it is the juxtaposition of various points of view - Israeli, Palestinian, Christian, members of Médecins Sans Frontières, and his own - that make it his best.

\section{The maintenance of selfhood in a foreign land}

The verbal and visual storytelling techniques of the autobiographic comic, if we take a wider definition of autobiography, were specifically chosen to convey Delisle's interest in the dynamics between Self and Otherness, as revealed in his travel books: "the cartoon is a vacuum into which our identity and awareness are pulled [...] An empty shell that we inhabit which enables us to travel in another realm" (McCloud 1993, 36). His cartoonlike self-portrait - or auto-image - is comprised in a few jauntily drawn lines with dots for eyes. He carefully draws portraits of the Other, sometimes real situations and other times imagined characters, such as the gallery depicting the six religious orders that share custody of the Church of the Holy Sepulchre: "Ethiopian Orthodox, Armenian Apostolic, Roman Catholic, Greek Orthodox, Coptic Orthodox, and Syrian Orthodox” (111).

But these representations - or, rather, representamen (Leerssen 2007) - inked tightly in perfect capital letters, carefully drawn between the lines of each panel -, are more than cultural and national stereotypes. Jerusalem implicitly "raises a claim of referentiality vis-à-vis empirical reality" (Leerssen 2007, 27), and the reader of Jerusalem is, nevertheless, likely to seek evidence of identity and of authenticity in the form of a resemblance between the drawn characters, places or sacred monuments, and their extratextual models. Yet these are "imagetext" tropes which reinscribe, within the worlds of visual-verbal representations, the 
shifting relations of names and things, the sayable and more specifically the seeable, discourse (Mitchell 1994) about and the experience of living in Jerusalem. It would seem, then, that the Self and Other can be both visually and verbally described in graphic novels, which allows not only for the identification of the extratextual models within the panels and the source of the dialogue in speech balloons, but also with the verbal narrator voice-overs and the compositions within the panels.

There is an interesting dynamic between those images which characterise Otherness, the foreigner, the non-Western cultures - hetero-images (Leerssen 2007,27 - and ones which characterise one's own national identity. Likewise, in Jerusalem there is an interesting shift that takes place: having been invited to the Freedom of Speech Festival in Norway, and then to a Comics Festival in Helsinki, the protagonist has to travel to Northern Europe. On his way back to Israel, at the check in for his Paris-Tel Aviv flight he is retained by the authorities for having mentioned that his wife, a member of the Médecins Sans Frontières, works in Gaza. Being a Canadian is not at all complex and problematic, but being married to someone who works and temporarily is being kept in the Gaza camps engraves a new identity of Delisle in the eyes of the French authorities. He has to reaffirm his own identity as a Canadian citizen and a cartoonist, when he is in fact treated not only like an outsider, a foreigner, but also as a possible menace to national security: "It all ends in the office with me browsing the Finnish festival site to prove that I was on the list. 'I even won a prize. A nice little statue'” (61).

Guy Delisle is a subjective, self-ironic and thus a humorous source (Leerssen 2007): "I often see a neighbour who goes out covered head to foot. She even has gloves. I don't know how she puts up with it in this heat [...] And whenever I see her I always wonder: why not go all the way and wear dark glasses too?” (69-70). But the irony of his own situation is not lost on Delisle: he is supposed to play the role of a "housewife" and help take care of the two young children while their mother is out doing real work and making a difference: "For instance, since it's Ramadan this week, Alice ends an hour early. I pick her up on foot. We take a minibus. We drive downtown. We pick up Louis. We return by minibus. And we walk home. In short, the glamorous life of a housewife" (51).

The protagonist spends most of his days transporting his own children in a city of major violent conflict, with non-existing sidewalks, cratered roads, and random parking. One might have imagined that "Jerusalem would be much more modern. It sure didn’t look like this in the travel guides” (14). Once again, Delisle contrasts a general perpetuated image of the Holy Land: "Bethlehem is in the west bank, so you need to drive along the wall and go through a massive checkpoint. Result: travellers set out for Bethlehem with this image in mind [...]" - a warm, welcoming representation of the Nativity of Christ - "[...] and return to this one," - high, taciturn walls surrounding the Church of the Nativity. 
The twelve chapters of the book contain stories of human minutiae in a place we only see in times of political strife on the news, when it blends into all the other stories of political discord and we become numb to it. Without Delisle we might never learn what it is actually like to live in a place like this, or get a realistic idea of the people we would meet if we did. Many of the vignettes are about how all these things affect him and most importantly the children, who are frequently on the rough end of a conflict they do not understand: "The guns are end-of-Ramadan gifts. Given the context, I'd probably give them Lego bricks instead” (69).

Guy Delisle's Jerusalem: Chronicles from the Holy City is a nonfictional graphic novel about being far away from home in an occasionally dangerous and precarious and confusing place. It is about living for a year in Israel while trying to be a husband, a father, and an itinerant cartoonist - "Whoa, I haven't sketched in ages." He confesses in one of his interviews that during the year he spent in Jerusalem he was not sure that this experience was going to turn into another graphic novel. That he had indeed written and published a volume based on his year spent in Jerusalem is indicative of the fact that he had a great interest in it.

An imagological interpretation does not need to discern how much fact and how much fiction exist in Delisle's travel stories in order to decide whether they are a reliable source of representation of the things they account for or not, mostly because "the demarcation between imaginated discourse and testable report statements is not always obvious" (Leerssen 2007, 28). There are numerous occasions in which the information comes from locals, Israeli and Arabs alike, in this way the readers are comforted that he is given first-hand facts, unprejudiced by travel writer's ignorance, misunderstanding or wrong interpretation. This also means that Delisle had meant to create as vivid a tableau of Jerusalem as possible, in order to make his account more attractive to its target audience: readers of autobiographical comics and graphic novels, as well as of contemporary travel books about the Holy City. Accordingly, it is highly plausible that the writer also embellished things with his imagination, by inventing characters to fill in his ingenious panels, as well as selecting specific events in his account which "singles out a nation from the rest of humanity as being somehow different or 'typical'” (Leerssen 2007, 28).

There is a nice cross-section of Jerusalemite society in the park, where we see Orthodox Jewish mothers, Muslim mothers, and Delisle himself watch their children run across the playground captioned by: "The kids mix easily. And sometimes adults do too" (64). People in and around Jerusalem are separated by their traditions and customs, and - with very few exceptions - they rarely mingle. Delisle seems more like a fish-out-of water everyman character, caught up in an order of things that has been going on for centuries. The chapter entitled "September" creates a vibrant image of east Jerusalem during the Ramadan: "Ramadan started a few days ago, and the local houses are all decked 
out with lights. The themes look borrowed from another holiday. There's even a snowflake. At 30 degrees Celsius, the effect is a bit odd" (36). The brightly coloured decorations which the locals seem to have prepared expressly for Ramadan resemble those types of ornaments used to light up a house and decorate a holiday tree at Christmas in the Western world. He even describes Tel Aviv a "normal" city with "normal" people for favouring a more "Western" lifestyle. The similarities, however, end here.

Guy Delisle, as many other graphic memoirists, is typically less concerned with trying to capture people's outer appearance as accurately as possible and more with expressing character traits and shifting states and emotions (El Refaie $2012,147)$. His work is highly self-referential, in that he occasionally addresses the process of writing comics and the lack of social status this typically affords. In the final panel of his Finnish experience, we see him desperately trying to convince the unflinching officer with a caption that reads "I really did win a prize, I swear!" (61). The self-portraits scattered across Jerusalem: Chronicles from the Holy City always reveal something "deep and incontrovertible" about the inner self of the artist and how he hopes to be seen: moments of solitude, sketching outside the Wall or by a refugee camp contemplating the Israeli landscape, on the Mount of Olives or up in the tower of the Augusta Victoria Church. Delisle's drawings of himself are sometimes able to convey much more effectively his state of mind than the speech balloons attached to the images. The focus of the visuals is more on the subjective experience of the time spent in a foreign land.

The dynamic between the written code - speech and thought balloons, descriptive tags affixed to particular people and places in individual panels -, and the pictorial code is another aspect to be taken into account in an imagological interpretation of the relationship between the sense of Self and the perception of the Other. One might tend to define the images which characterize the Other in terms of being "realistic" or "unrealistic," referring to Delisle's drawing style, and this distinction may prove itself useful to analyse these hetero-images (Leerssen $2007,27)$ more precisely. For example, in his exemplification of the six religious orders sharing custody of the Church of the Holy Sepulchre, Delisle draws six characters (111) in the form of "amplification through simplification" (McCloud 1993, 30), where unnecessary details are left out in order to focus on the essential: the symbols of each order.

In Peirce's (1960) semiotic theory, words and images are seen as fundamentally different kinds of signs. Words are "symbols," based on arbitrary connection between a signifier and a signified; their meaning is completely dependent on conventions. Images, on the other hand, are "icons," which are founded on a close physical resemblance between signs and their meaning. According to Peirce's definitions, comics and graphic novels lack the indexical quality of photographic representations in that they do not resemble the represented objects quite so 
closely. Thus, the more simplified a drawing is, the more it acquires "symbolic" qualities. What makes this approach particularly attractive to our purpose is that it suggests a way of addressing the relationship between such stylistic features and perceptions of truthfulness, which brings again into discussion Leerssen's distinction between "imaginated discourse" and "testable report statements" $(2007,28)$. The drawing of the markets and the people in the streets of Jerusalem tends toward abstraction using the "universally accepted scribbles that stand in for what mouths and noses and motion and sweat look like" (Wolk 2007, 120). There is a humorous moment where Delisle contrasts his style of drawing with what would be perceived as a more realistic one. During the municipal elections posters for the main candidates were "plastered all over the city," and "one rabbi had himself portrait in cartoon form" (145), the poster resembling the cartoonist's abstract style of drawing. Below, in an individual panel we read: "His PR team must have convinced him not to use a photo, which makes sense, since he actually looks like this" next to a fairly detailed, more realistic-looking image. Stylistic realism is not the most common cue to authentic intention: "although the visual style of a comics artist is an important authentication strategy, it often draws its power less from its iconic resemblance to reality than from the indexical clues it seems to offer about the artist's genuine characteristics and intentions" (El Refaie 2012, 155). Patterns of "Othering" (Leerssen 2007, 29) can be easily identified in single panels or along sequences of images, as the residents of the heavily contested territory - Jewish, Muslim and Christian - keep to their rightful place, just as Delisle acknowledges his own: the outsider, sitting on a hill, drawing or going about the minutiae of his day-to-day.

Inscribing travel writings in the field of autobiographical comics and graphic novels and attempting to circumscribe its characteristics within the sharp contours of the sequential art proves to be a profitable affair. Comics in general, and graphic novels in particular, are a multimodal medium allowing through imagological methods and perspectives to focus on both the textual and pictorial codes, redefining the specificity of literary imagology, graphic novels thus contributing to the growing interest in identity constructs.

Jerusalem: Chronicles from the Holy City also won the Best Comic Album Prize (the Fauve d'Or) at the 2012's International Comics Festival in Angoulême, France, making Guy Delisle the first Canadian cartoonist to win this prestigious honour. Wisely enough, Delisle never divulges outright with whom he sympathises. The final page of Jerusalem, the image of the plane above the clouds, leaving Israel, reminded me of the defeated sentiments of a street vendor whom the protagonist met in the first month of his visit, and who, prompted by Delisle's mention of Doctors Without Borders, wearily responds: "There'll always be borders." 


\section{Works cited}

Delisle, Guy. 2012. Jerusalem: Chronicles from the Holy City. Trans. Helge Dascher. Montreal, Quebec: Drawn and Quarterly.

El Refaie, Elizabeth. 2012. Autobiographical Comics: Life Writing in Pictures. Mississippi, Jackson: University Press of Mississippi.

Holland, Patrick and Graham Huggan. 2000 [1998]. Tourists with Typewriters Critical Reflections on Contemporary Travel Writing. Ann Arbor, Michigan: The University of Michigan Press.

Leerssen, Joep. 2007. Imagology: History and Method. In Imagology: The Cultural Construction and Literary Representation of National Characters. A Critical Survey, eds. Manfred Beller and Joep Leerssen (Studia Imagologica, Vol. 1), 17-33. Amsterdam and New York: Rodopi Publishers.

McCloud, Scott. 1993. Understanding Comic. The Invisible Art. New York: HarperCollins Publishers.

Mitchell, W. J. Thomas. 1994. Picture Theory: Essays on Verbal and Visual Representation. Chicago and London: University of Chicago Press.

Obenzinger, Hilton. 2009. Americans in the Holy Land, Israel, and Palestine. In The Cambridge Companion to American Travel Writing, eds. Alfred Bendixen and Judith Hamera, 145-164. Cambridge and New York: Cambridge University Press.

Peirce, Charles Sanders. 1960. Collected Papers of Charles Sanders Peirce, Volume II: Elements of Logic. Charles Sanders Peirce and Paul Weiss, eds. Cambridge, MA: Harvard University Press.

Świderska, Małgorzata. 2013. Comparativist Imagology and the Phenomenon of Strangeness. CLCWeb: Comparative Literature and Culture vol. 15. no. 7. http://dx.doi.org/10.7771/1481-4374.2387 (12 Apr. 2015)

Vollmar, Rob. 2012. Jerusalem: Chronicles from the Holy City by Guy Delisle. World Literature Today vol. 86. no. 6 (November/December): 60-61. http://www.jstor.org/stable/10.7588/worllitetoda.86.6.0060 (10 Apr. 2015)

Wolk, Douglas. 2007. Reading Comics: How Graphic Novels Work and What They Mean. Cambridge, MA: Da Capo Press.

\section{Acknowledgment}

This work was supported by the strategic grant POSDRU/159/1.5/S/140863, Project ID 140863 (2014), co-financed by the European Social Fund within the Sectorial Operational Program Human Resources Development 2007 - 2013. 